\section{DO YOUR MARKETING GROUNDWORK}

Many people wrongly believe that marketing is simply advertising. True marketing requires knowledge and understanding of your business, knowledge of your products, services and your customer base, according to the British Dental Association (BDA) business team.

Advertising is how best to target that 'type of person' in a way to get them through your door. They cite knowing your business, your goals and your patients as important steps to success.

For more information about ways to positively improve your business, visit www.bda. org/advicesheets to read its 'Marketing in Dentistry' advice sheet (A6) or call the BDA business team on 02075355864 .

\section{DECAY DETECTION}

The CarieScan Pro measures the presence of tooth decay early and accurately and is $92.5 \%$ accurate in detecting both sound and carious teeth. It can also detect hidden decay, driving the trend towards preventive dental care.

The Pro measures the demineralisation of enamel. The device is currently configured to assess the occlusal surfaces and the free-smooth surfaces of teeth. There is no pain, no sensation and no ionising radiation - simply the touch of the sensor on a patient's tooth. Readings are clear and easily understood by patients.

Call 08454759873 or visit www.cariescan.com for more information.

\title{
RE-USABLE BADGES
}

Badgemaster, manufacturer of custom made, ready-to-wear employee name badges has launched a new product range.

InstaBadge enables employers themselves to create instant name badges for new starters and staff changes and they can also be reused.

The credit crunching product is ideal for workplaces with frequent staff changes. The wearer's name is held on ordinary card or paper within the badge rather than engraved onto it. The new range includes six different styles, all available in any base colour and with plenty of space for individual corporate designs and logos.

Its unique moulding combines an integral fastener as part of the badge, so avoiding the chances of the pin or badge becoming accidentally detached. For more information call 01623 723112 or log on to www.badgemaster.co.uk.
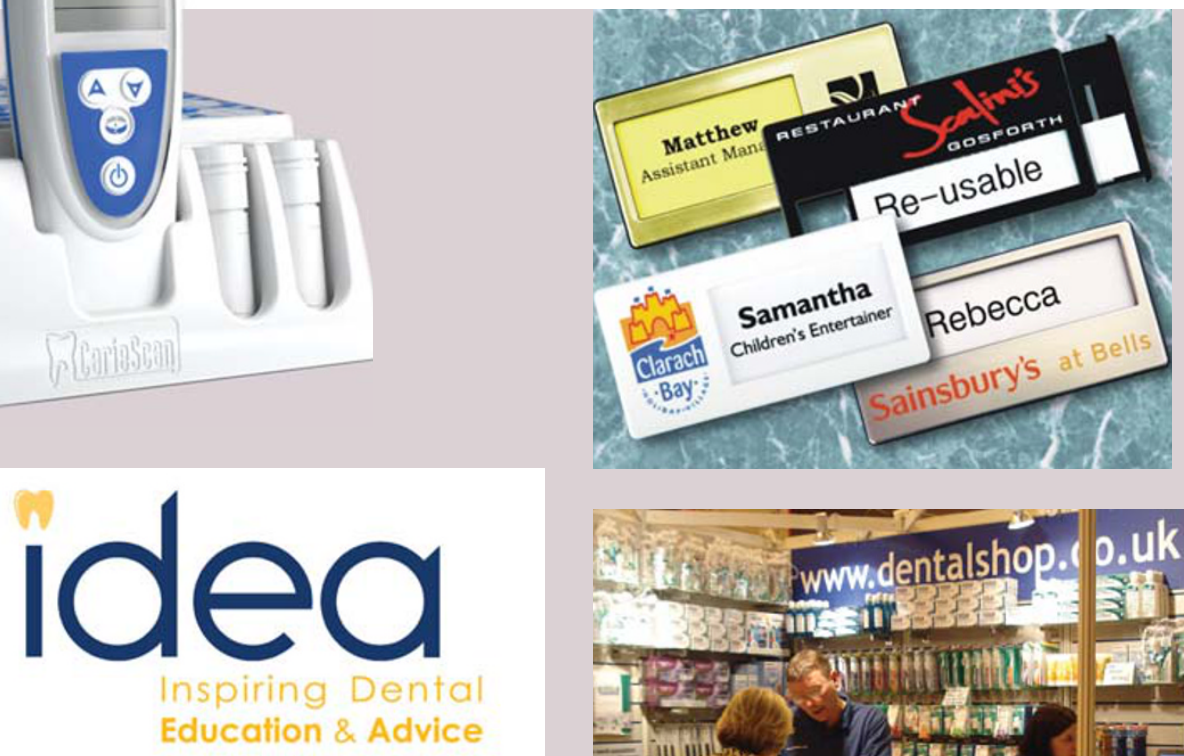

\section{PAINLESS DELIVERY}

Quicksleeper is a computer controlled local anaesthetic system that delivers profound anaesthesia quickly, easily and painlessly. Dentists can perform osteocentral anaesthesia whereby a small amount of conventional local anaesthetic is placed in the spongy bone in between teeth.

Eliminating the need for painful infiltration, it can be used when treating children and other potentially nervous patients. As it acts locally and does not create lingual anaesthesia or the 'thick lip' associated with ID and Mental Blocks, there is no risk of the patient biting the lip and it is safe to use bilaterally on the mandible.

Using Quicksleeper it is possible to anaesthetise between two and eight teeth with just one injection without the need for additional palatal or buccal injections.

Call General Medical on 01380 734990; or visit www.general-medical.co.uk.

\section{MANAGING CPD}

Education website IDEA (Inspiring Dental Education and Advice) is helping its members through their CPD. Members can access the Resource Section of the IDEA CPD Management System free of charge.

In the Resource Centre, they will find a range of technical articles available to download. By answering the related questions, members can typically earn one hour of CPD per article.

The site also provides access to a free online Cross Infection Control (CIC) course. This provides a solution to the five hours of CIC recommended by the GDC.

DCPs will need to enter the course on their CPD record, which must be presented if requested by an audit.

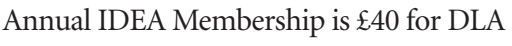
Members and $£ 50$ for non-DLA Members; visit www.ideacareers.co.uk.

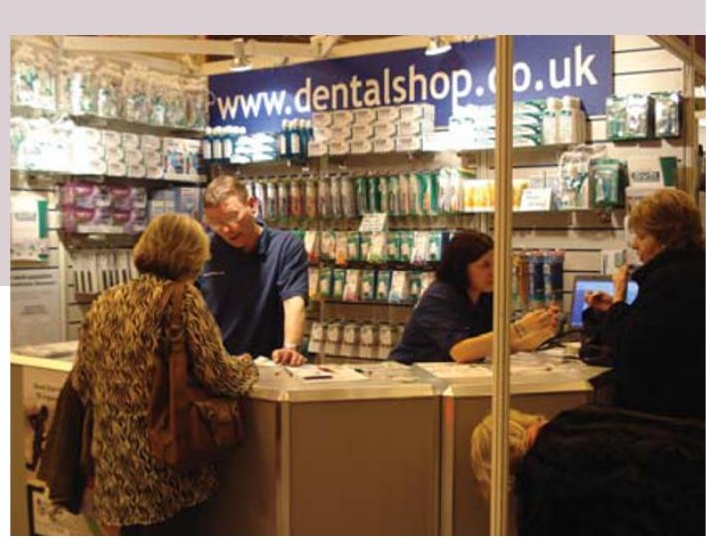

\section{SHOW SUCCESS}

The recent 2009 Vitality Show held at Earl's Court in London gave dental product provider www.dentalshop.co.uk a chance to meet its customers face to face. Top products of the day included GUM Softpicks, flexible rubber bristles that slide between teeth to help safely remove plaque and food particles; GUM Tongue Cleaners designed for optimal cleaning and fresher breath with two rows of bristles and scrapers; and Sunstar GUM Original White oral hygiene products which achieve a naturally white smile without harsh bleaching. 